\title{
Rachando o campo psi-jurídico: pistas para (des)caminhos formativos
}

\author{
Cracking the psycho-legal field: traces to training (mis)paths
}

\section{Renata Ghisleni de Oliveira}

Núcleo de Pesquisa em Psicologia Jurídica do Conselho Nacional de Desenvolvimento Científico e Tecnológico (NPPJ-CNPq).

\section{RESUMO:}

$\mathrm{O}$ artigo apresenta desdobramentos da pesquisa de doutorado, na qual foram estudados os encontros entre psicólogos, assistentes sociais e defensores públicos na Defensoria Pública do estado de São Paulo. Utilizando-se da pesquisa-intervenção como estratégia metodológica, acompanharam-se diferentes arranjos organizacionais que possibilitaram se deparar com modalidades diversas de interprofissionalidade. Em diálogo com o pensamento foucaultiano e com a filosofia da diferença, serão apresentadas experiências que sinalizam a emergência das dimensões "entre" e coletivas das práticas na Defensoria Pública paulista. Evidenciou-se que é justamente no front desterritorializado desse inédito combate - dessas outras modulações de encontro - que ganham relevo as forças mais que as formas e fôrmas, a intensidade, ao invés da identidade. Os itinerários de formação acompanhados na pesquisa abriram caminhos para problematizar a noção de campo psi-jurídico como unidade fechada e identitária e para pensar nas interferências que supõem o permanente exercício do entre posições e possibilitam o jogo da diferenciação.

Palavras-chave: Defensoria Pública; campo psi-jurídico; interdisciplinaridade.

\begin{abstract}
:
This article presents doctoral research deployments in which where studied encounters between psychologists, social assistants and public defenders at Defensoria Pública do Estado de São Paulo. Using intervention-research methodology different organizational arrangements were accompanied that made it possible to come across different modalities of interprofissionality. Dialoguing with foucaultian thinking and with the difference philosophy, experiences will be presented that signalize the emergence of dimensions "amidst" and collective in the practices at Defensoria Pública do Estado de São Paulo. It was evidenced that, precisely in the deterritorialized front of this unprecedented combat - of these other encounters modulations -, forces earn more importance than shapes and forms, and intensity, instead of identity. The training itineraries followed in the research path made way to problematize the psycho-legal field notion as closed unity and identity and to think about interferences that suppose the permanent exercise of amidst position and enable the differentiation game.
\end{abstract}

Key-words: Public Defender; psycho-legal field; interdisciplinarity. 


\section{Introdução}

A escolha por estudar os encontros psi-jurídicos está ligada às inquietações produzidas a partir de percursos profissionais e de pesquisa experenciados pela autora na interface com o Direito. Estas indagações se inserem num contexto mais amplo de tensionamentos, disputas, alianças e coexistências no campo psi-jurídico, compreendido como um espaço inseparável das táticas de normalização (FOUCAULT, 2006), fazendo deste um importante espaço de análise dos saberes e das práticas psicossociais. A conformação deste campo e a problematização de seus efeitos foram objeto da pesquisa de doutorado da autora, que estudou os encontros entre psicólogos, assistentes sociais, defensores públicos e estagiários das referidas áreas na Defensoria Pública do estado de São Paulo. Aposta-se que a análise crítica destas práticas contribui para complexificar o debate e arguir os modos pelos quais psicólogos, assistentes sociais e operadores do direito que atuam nesse campo pensam e fazem sua formação e exercício profissional.

No bojo desta discussão, elegeu-se a Defensoria Pública paulista como lócus da pesquisa empírica por ser uma organização do sistema de justiça que pode dar visibilidade às necessidades da população pobre que, historicamente, teve e tem, muitas vezes, suas demandas menorizadas ${ }^{1}$ A Defensoria Pública é um órgão do sistema de justiça, previsto na Constituição Federal de 1988 e visa garantir acesso à justiça à população pobre que, nos critérios da lei, tem renda familiar de até três salários-mínimos. Diferentemente da saúde, não é uma política pública de acesso universal, utilizando critérios socioeconômicos para definir o público-alvo de suas ações (OLIVEIRA, 2015).

Em São Paulo, a Defensoria Pública foi criada em 2006, sendo a organização mais recente a compor o cenário jurídico paulista, e apresenta uma série de propostas consideradas inovadoras que orientam suas ações, dentre elas: Momento Aberto da Defensoria (espaço de diálogo com o Conselho Superior - órgão deliberativo máximo da organização), ciclo de conferências públicas (encontros com a população para debater sobre suas principais reivindicações e construir parâmetros para atuação da defensoria) e intervenção interprofissional com psicólogos e assistentes sociais (ocorre em duas frentes ${ }^{2}$ : nos Núcleos Especializados - dividem-se em temáticas específicas: infância e juventude, direitos da mulher, situação carcerária, entre outras, subsidiando diretrizes institucionais para atuação nesses temas - e nos Centros de Atendimento Multidisciplinar-CAMs) (OLIVEIRA, 2015). 
Os CAMs estavam previstos desde a criação da Defensoria Pública, mas iniciaram suas atividades em 2010 com o ingresso dos primeiros psicólogos e assistentes sociais no quadro permanente da organização. São locais de atuação de profissionais e estudantes de psicologia e serviço social que se destinam a garantir um atendimento integral aos cidadãos que procuram assistência jurídica nas diferentes regiões do estado (capital, região metropolitana e interior).

Os encaminhamentos ao serviço são feitos por operadores do direito (estagiários de direito e defensores públicos) que, após realizarem triagem dos atendimentos, solicitam a atuação psicossocial, em geral nas questões que envolvem conflitos familiares, dependência química, demandas criminais e necessidade de acesso a outras políticas públicas, especialmente nas áreas de assistência social e saúde mental (OLIVEIRA, 2015). Segundo Paula Rosana Cavalcante (2015), psicóloga da Defensoria Pública paulista, o trabalho do CAM pode ser organizado em quatro eixos de atuação, quais sejam: atendimento psicossocial, composição extrajudicial de conflitos (resolução das demandas conflitivas por meio de acordos sem gerar uma ação judicial), mapeamento e articulação com equipamentos de outras políticas públicas, participação em atividades de educação em direitos e formação e produção técnica (elaboração de pareceres, relatórios, laudos, quesitos, entre outros documentos).

Em diálogo com os estudos de Sônia Altoé (2001), Esther Maria de Magalhães Arantes (2008) e Leila Maria Torraca de Brito (2012), que problematizam o saber-fazer da Psicologia junto ao Direito, e levando em conta a ampliação da presença psi e psicossocial nos contextos do sistema de justiça para além dos tribunais, na Defensoria Pública e, também, recentemente, no Ministério Público, produziram-se questionamentos: a entrada de psicólogos e assistentes sociais numa organização que visa à promoção, luta e garantia dos direitos de uma população historicamente marcada por entraves no acesso à justiça poderia suscitar arranjos mais transversais e cogestionários no cenário jurídico? O que se passa entre Psicologia, Serviço Social e Direito na Defensoria Pública? Como acontecem as práticas entre profissões na Defensoria Pública? Poderiam estes encontros sinalizar a emergência de modos de fazer menos disciplinares ou até mesmo “desdisciplinares” (RODRIGUES, 1998)?

O percurso de pesquisa na Defensoria Pública do estado de São Paulo teve duração de quase dois anos, entre agosto de 2011 e dezembro de $2013^{3}$. Esta experiência possibilitou entrar em contato com diferentes arranjos organizacionais no processo de trabalho e com alguns de seus efeitos. Não foram poucas as inquietações suscitadas no decorrer da pesquisa, uma vez que 
o acompanhamento de processos evoca um misto de acontecer vivido e inventado (MERHY, 2013), cheio de armadilhas, riscos e desafios.

O pesquisar valeu-se de alguns espaços potentes de encontros psi-jurídicos, dentre eles: a) participação em eventos organizados pela Escola da Defensoria Pública (Edepe) - seminários e rodas de conversa com profissionais; b) entrevistas com defensores que acompanharam a criação da Defensoria Pública em São Paulo; c) participação em projeto de formação de grupos com defensores ${ }^{4}$ e em projeto sobre as práticas interdisciplinares proposto por estagiário do $\mathrm{CAM}^{5}$; e d) o acompanhamento das práticas de uma equipe CAM localizada na capital.

A metodologia utilizada foi da pesquisa-intervenção, com ferramentas conceituais da Análise Institucional Francesa (BAREMBLITT, 2002; LOURAU, 2001; 2004). A pesquisaintervenção emerge do Institucionalismo francês, desenvolvido entre as décadas de 1960 e 1970 (RODRIGUES, 1999; 2004). Este modo de produção de conhecimentos possibilita a análise das instituições, questionando os seus sentidos dados como naturais. Nesta perspectiva, as instituições descolam-se da ideia de estabelecimento e se referem ao processo de produção constante de modos de legitimação de práticas sociais e incluem a maneira como os sujeitos concordam ou não em participar daquilo que regula suas vidas e condutas (LOBO, 2004; LOURAU, 2004; PASSOS e BARROS, 2000).

As experimentações e os encontros produzidos na pesquisa foram registrados por meio da elaboração de diários. O diário de campo, ferramenta-estratégia utilizada pela análise institucional, possibilita reflexões sobre "o pesquisar" a partir da análise das relações implicadas nessa experiência. Ele tem o potencial de explicitar as linhas de força e de tensão de dada situação social que, ao serem expostas, afetam e deixam afetar-se, produzem e transformam a realidade (LOURAU, 2004).

Neste artigo, em diálogo com o pensamento foucaultiano e com a filosofia da diferença, serão apresentadas experiências que sinalizam a emergência das dimensões "entre" e coletivas das práticas. E é justamente no front desterritorializado desse inédito combate - dessas outras modulações de encontro - que ganham relevo as forças mais que as formas e fôrmas, a intensidade, ao invés da identidade. Os itinerários de formação acompanhados no percurso da pesquisa abriram caminhos para problematizar a noção de campo psi-jurídico como unidade fechada e identitária e para pensar nas interferências que supõem o permanente exercício do entre posições e possibilitam o jogo da diferenciação. Diferença, no sentido que Gilles Deleuze 
(2018) lhe confere, como afirmação de singularidades, de potências e de transitoriedades, em oposição radical à ideia de identidade conceitual e representação amparada na universalidade.

\title{
Itinerários de formação na Defensoria Pública paulista: entre formas, fôrmas e forças
}

\begin{abstract}
Sobre essa questão de ser ora multi ora interdisciplinar, eu penso que deve ter sido algum problema na montagem da lei [referindo-se ao nome do serviço ser Centro de Atendimento Multidisciplinar]. Na época da elaboração do projeto de lei da Defensoria, nós já tínhamos uma bagagem bastante crítica, já tínhamos para nós que a interdisciplinaridade possibilitava trocas mais efetivas. A multidisciplinaridade é um primeiro passo, pois garante conhecimentos múltiplos. No entanto, ela não dá conta da complexidade dos fenômenos que encaramos no dia a dia. Entendo que é um processo, começa na multi para chegarmos em outras coisas, é um grande desafio. As práticas interdisciplinares na Defensoria estão em construção. A interdisciplinaridade é algo que almejamos e, para acontecer, requer que os conhecimentos se entreguem, opa, se integrem. (Defensor público - entrevista cedida para a pesquisadora em: 30/10/2012).
\end{abstract}

Tomemos a pista acima enunciada pelo defensor público para pensarmos nos efeitos dos encontros entre saberes na Defensoria Pública: para que aconteçam é necessário que os conhecimentos se entreguem, se lancem no entre. Por certo, este movimento não constitui tarefa fácil, uma vez que o mundo do trabalho e da prática educativa tende a (re)produzir fragmentações, conhecimentos disciplinares e desintegrados, emergindo formações que operam por modelos privatizantes e individualizantes que minimizam questões históricas e políticas na constituição da subjetividade (LAZZAROTTO, 2009).

Nas ditas "ciências humanas" ainda vigora uma visão "aplicacionista", pautada na compreensão de que conhecemos para transformar, de que produzimos conhecimentos a serem utilizados numa realidade supostamente já dada, pronta. Esta perspectiva de formação costuma voltar-se à reprodução do já apreendido, à busca de uma maneira "correta", supostamente "certa" de fazer, reduzindo o aprender ao treinamento de habilidades e competências, dissociadas de um campo de intervenção (HECKERT e PASSOS, 2009).

A compreensão de formação afirmada no presente estudo dialoga com as críticas apresentadas acima, forjando-se a partir dos seguintes elementos: um processo que envolve aspectos culturais, econômicos e sociais (FERRETTI, 2008); articulação entre teoria e prática (DE SORDI e BAGNATO, 1998; FERREIRA NETO, 2011); os processos de trabalho constituem sua matéria-prima (HECKERT e PASSOS, 2009); diz respeito às políticas de produção de novos modos de pensar, sentir e agir (HENZ, 2009); produzida entre a invenção de si e do mundo (KASTRUP, 2007; LAZZAROTTO, 2009). 
A "formação", no sentido amplo, é um processo que também transpassa escolas e universidades, mas que não se restringe ao aspecto profissional ou acadêmico (RODRIGUES, 1998). Para Ana Lúcia Coelho Heckert e Eduardo Passos (2009), todo fazer é produção de si e de mundos, sendo que os processos de formação interferem nos sujeitos, com a potência de desestabilizar modos instituídos de existência. Compreender a formação, a produção do saber, como processos de coemergência de si e de mundo nos abre a possibilidade de fazê-la funcionar como um dispositivo potente de intervenção, como usina de produção. Nesse sentido, a formação deixa de ser um espaço tranquilo de transmissão do conhecimento para mostrar os embates de forças, de confronto entre as formas já estabelecidas e as forças de mudança. Desse modo, temos afirmado a formação como "potência disruptiva" (HECKERT e PASSOS, 2009: 383).

Retomemos o sentido da intervenção em Análise Institucional. Seu enunciado não pode estar dissociado, separado ou descolado das condições sociais que permitem ou não materializála, sob o risco de esta ficar reduzida apenas a uma boa intenção ideológica (LOURAU, 2001). A isto, precisamente, ou seja, à organização destas condições, se chama dispositivo, que não se deve confundir com dispositivismo, (neologismo de René Lourau para designar a versão instrumentalista desta noção).

No tempo da intervenção, tempo crítico, certas deslocalizações espaço-temporais das práticas cotidianas se operam. Assim, tomando a perspectiva de uma formação como dispositivo de intervenção, apostamos na sua potência de transformação das práticas profissionais e da própria organização do trabalho ao orientar-se a partir da problematização do processo de trabalho (CECCIM e FEUERWERKER, 2004).

No percurso da pesquisa na Defensoria Pública paulista, foram acompanhadas algumas experiências que têm privilegiado problematizar estas questões. O que interessará olhar, nestes fragmentos de cenas vividas com os sujeitos de pesquisa, são as perturbações e interferências (LOURAU, 2004) que as modalidades de encontro com o outro (OURY, 1991) produzem no processo formativo. Segundo René Lourau, “as interferências não são interseções geométricas (morfologicamente traçáveis) de linhas-fronteiras. São as ações, os acontecimentos, as forças que criam, modificam e desfazem as formas, à procura de uma transversalidade, de um equilíbrio que não é o equilíbrio homeostático da teoria dos sistemas, mas o de uma capacidade de autonomia (sempre posta em questão)" (LOURAU, 2004:181). 
Na literatura, encontram-se diferentes compreensões para as noções de multi, inter e transdisciplinaridade. Para Augusta Thereza Alvarenga (2011) e Hilton Ferreira Japiassu (1977), a multidisciplinaridade costuma ser associada ao tratamento de um tema, assunto ou situação sob diferentes pontos de vista, ou seja, com profissionais de diferentes formações, sem que haja troca efetiva entre os saberes. Esse arranjo mostra um primeiro movimento na direção de superar o isolamento dos territórios disciplinares. No entanto, a multidisciplinaridade não provoca modificações no saber disciplinar de cada profissional nem no sentido do objeto; sendo assim, não altera a relação entre sujeito e objeto do conhecimento. A interdisciplinaridade também supõe a atuação de profissionais com diferentes formações; no entanto, o encontro destas diferenças possibilitaria a construção de outros instrumentais, ferramentas e conhecimentos. Assim, constitui-se numa forma de operar baseada na troca de experiências e saberes e no desenvolvimento de outras perspectivas e fazeres, porém sem abalar os limites daquilo que cabe a cada um (ALVARENGA, 2011; JAPIASSU, 1977).

Para Eduardo Passos (2013), a interdisciplinaridade se configura numa modulação da multidisciplinaridade, sendo um modo de aproximar as disciplinas para a compreensão da complexidade que vem a produzir uma zona de interseção entre elas. Esta zona de interseção corresponde a um espaço de conjugação de dois domínios para a constituição de um terceiro, de uma nova identidade. Este movimento produz a multiplicação dos territórios disciplinares, gerando outros sujeitos e objetos próprios a partir desse movimento entre os saberes. E a transdiciplinaridade? A transdisciplinaridade vem sendo compreendida como um modo de pensar-intervir no qual os limites das fronteiras entre as disciplinas são tensionados com radicalidade (PASSOS e BARROS, 2000), levando à produção de novos paradigmas através da articulação entre diferentes campos do saber disciplinares, operando na lógica da multiplicidade (FERNÁNDEZ, 2008). Ana María Fernández (2008) utiliza o pensamento de Gilles Deleuze e, posteriormente, o de Cornelius Castoriadis para forjar uma noção de multiplicidade que opera pela lógica do "e", a qual liga, conecta diferentes objetos entre si. Esta perspectiva contrapõe-se às divisões binárias e homogêneas.

Passos (2013) define a transdisciplinaridade como

uma relação entre as disciplinas a partir da diferença que as une. Há uma aproximação pela distância ao se criar um efeito de perturbação entre as diferentes disciplinas. Produz-se entre as disciplinas não uma interseção, mas uma intercessão (Deleuze, 2010). Cria-se uma zona de perturbação entre uma disciplina e outra, havendo uma experiência de modificação, de alteração do território disciplinar. Não se acaba com uma disciplina nem se cria outra: é a psicologia transformada, a medicina transformada, a terapia ocupacional transformada. A 
função intercessora faz modular o território disciplinar, possibilita sua transformação (PASSOS, 2013: 226).

Aqui, o conceito de intercessor nos ajuda a pensar a noção de transdisciplinaridade pelas conotações de desvio ou deriva que ele comporta ou ainda na sua acepção de correlação (RODRIGUES, 2010). No texto intitulado “Os intercessores”, Deleuze (2010) é quem nos sugere a perspectiva da interferência criativa como o modo de pensar uma relação, ao contrário da sobreposição de códigos ou de territórios, operando efeitos de sobrecodificação de um campo sobre o outro. Há, assim, uma diferença radical das noções de interseção e intercessão. No primeiro caso, a relação é de conjugação de dois domínios na constituição de um terceiro, que se espera estável, idêntico a si e para o qual se pode definir um objeto próprio. É o caso, como vimos anteriormente, da interdisciplinaridade. Na transdisciplinaridade, a relação que se estabelece entre os termos que se intercedem é de interferência, de intervenção através do atravessamento desestabilizador de um domínio qualquer (disciplinar, conceitual, artístico, sociopolítico etc.) sobre outro (PASSOS e BARROS, 2000). Esta interferência criativa abre um leque de possibilidades de articulação dos regimes de verdade existentes ou, ainda, de invenção de outros regimes, de invenção de novas formas de coexistência e de transformação.

Profissional 1 (psicólogo): "O entendimento que eu tenho é que no multi se trabalha com as disciplinas lado a lado. O inter eu já trabalho com intersecção de atuações com uma definição conjunta. No transdisciplinar, eu já abro mão dessa referência disciplinar".

Profissional 2 (defensor público): "Pela lei da Defensoria Pública o nome do órgão é Centro de Atendimento Multidisciplinar, a finalidade, a atribuição é interdisciplinar e pode ser trans (risos). Eu queria que você, profissional 1, comentasse isso, por favor".

Risos.

(Roda de conversa PUC-SP, maio de 2012)

Ricardo Burg Ceccim (2004) propõe o “entre-disciplinar” como o encontro entre saberes em que cada fronteira disciplinar pode percutir na outra como intercessão por sua mudança, resultando em alteridade e aprendizagem. O entre-disciplinar constitui-se num lugar de sensibilidade e equilíbrio metaestável. Nesse "lugar-meio", encontram-se aprendizagens, alteridades, fragilidades de cada referência profissional e desestabilizações dos regimes de verdade. Para Emerson Merhy (2013), quando se habita um território fronteiriço, lugar que desterritorializa o disciplinar na busca de novos regimes de verdade, entramos no “entredisciplinar". Para o autor, a emergência do entredisciplinar marca a produção de um território comum, que se faz no encontro com o outro. $\mathrm{O}$ específico não existe sem a produção do comum-singular, que pertence a todos (MERHY, 2013). 


\section{A dimensão entre na Defensoria Pública paulista}

Esta disposição "entre" é uma experiência que atravessa as práticas na Defensoria Pública e opera aberturas e fechamentos. No percurso de pesquisa, acompanhamos momentos em que os profissionais sinalizam tais experiências.

a) No projeto de formação com grupo de defensores:

Teve um dia que chegou um caso de esquizofrenia e a coisa mais simples a se fazer era delegar. Não deleguei. Tentei conversar com ela e vi que era possível. Atendi e estou tentando resolver o caso (Trecho grupo com defensores, maio de 2013).

Tudo que discuti com o defensor mais antigo no seminário, achava que nunca iria me deparar. Atender as demandas de juventude infracional requer olhar para a dinâmica familiar (Trecho grupo com defensores, fevereiro de 2013, Cronista: Renata).

Eu tive experiências fantásticas com o CAM. Nos pedidos de internação por uso de drogas. Todas as vezes foi ótimo. Eles fizeram até uma visita domiciliar. Outra vez foi uma questão mais psi, eu não sabia o que fazer. Quem atendeu foi a assistente social e foi ótimo! (Trecho grupo com defensores, fevereiro de 2013, Cronista: Renata).

Eu trabalho na família. Atendo menos que o meu colega porque eu escuto, eu me envolvo. Arrisco dizer que faço papel de psicóloga, às vezes. Para mim, filho não tem que escutar briga de pai e mãe (Trecho grupo com defensores, fevereiro de 2013, Cronista: Renata).

b) No projeto proposto por estagiário CAM:

São lógicas diferentes de trabalho. O nosso trabalho, dos defensores, é de produção em massa; o do CAM é de menor escala e mais profundidade, como o nosso deveria ser. Temos muito o que aprender com eles. (Defensora, reunião elaboração projeto estagiário, agosto de 2013)

Só transversaliza antes de virar uma ação, pois só nesse momento é possível pensar em várias alternativas. Isso, em geral, acontece no Polo Família. As situações difíceis de atuar são aquelas em que já existe um processo, pois chega tudo pronto, fechado. (Reunião profissionais e estagiários CAM, setembro de 2013).

Só consigo encontrar diferentes possibilidades para enfrentar uma situação por trabalhar aqui, na Defensoria, com pessoas do Direito e da Psicologia. (Assistente social, discussão de caso, outubro de 2013).

c) Na roda de conversa, PUC-SP:

Eu tenho problemas temáticos que, mais do serem multidisciplinares ou interdisciplinares, eles são problemas antes das disciplinas: que obriga a todos ao exercício de sairem de suas disciplinas para resolverem alguns problemas (Psicólogo).

- Onde o que interessa é menos a especificidade da sua disciplina, mas a multiplicidade de olhares que você pode ter sobre problemas que são densos o suficiente, do ponto de vista 
estratégico, institucional para os quais vou precisar de mais do que a formação que eu tive na minha graduação ou na minha pós-graduação (Psicólogo)

- A lei não legisla sobre essas margens, mas o psicossocial também não dá conta... Porque a questão é uma questão social, política (Psicóloga).

A partir dos movimentos e inflexões feitas pelos próprios atores da Defensoria Pública neste fazer entre, que acompanhamos no percurso de pesquisa, acreditamos que o que menos interessa é o ideal multi, inter ou trans dos arranjos disciplinares, e sim os dispositivos transversais forjados no processo de trabalho e nos itinerários de formação. São eles que criam condições para invenção de uma "estética do caleidoscópio", como nos diz Heliana Conde Rodrigues (1998: 22).

A autora, ao nos lembrar de nossa "historicidade belicosa", em termos de genealogia de relações de força, de desenvolvimentos estratégicos e de táticas, que conforma certas práticas discursivas e não discursivas, destaca que aquilo que permite o surgimento de certas "formas de dizer" e "formas de fazer", em dado momento, diz respeito às "saliências e reentrâncias das práticas vizinhas", e não a algo nobre ou, até mesmo, pré-determinado. A autora propõe uma "estética de caleidoscópio" à configuração dos "campos disciplinares vizinhos", sendo as estratégias aplicadas aos domínios de saber nesta "caleidoscopização" as seguintes: "nem multidisciplinarizá-los nem inter-disciplinarizá-los, mas des-disciplinarizá-los e transversalizá-los" (RODRIGUES, 1998: 22-23).

A transversalidade é um conceito desenvolvido por Félix Guattari, em 1964, em estreito diálogo com o trabalho realizado pelo autor em estabelecimentos psiquiátricos. Guattari (2004) define a transversalidade como o aumento da comunicação entre diferentes níveis e diferentes sentidos das múltiplas forças que atravessam e compõem os processos, opondo-se à pura verticalidade e à simples horizontalidade. $\mathrm{O}$ "coeficiente de transversalidade" refere-se ao grau de comunicação e atuação institucional das múltiplas dimensões que atravessam e produzem os processos sociais e de subjetivação. O coeficiente de transversalidade opera aberturas e fechamentos. Levar em conta o coeficiente de transversalidade para pensar as práticas implica recorrer a uma espécie de "desterritorialização" de campos de visão e tomar como perspectiva ângulos mais transversais para o âmbito das realidades cotidianas.

A psicóloga e o assistente social do CAM fizeram relatórios incriveis em dois casos muito dificeis que eu atendi. O primeiro deles era de uma mulher acusada de tentativa de homicidio. Quando eu fiz o primeiro atendimento, percebi que havia outras coisas em jogo. Por isso, pedi ajuda dos profissionais do CAM e do Núcleo Especializado da Mulher. Durante os atendimentos, veio à tona toda uma situação de violência doméstica que ela vivia há muitos anos e que desencadeou a tentativa de homicídio. O relatório produzido para este caso 
possibilitou mostrar essa história e teve como efeito, na audiência, a fala do promotor dizendo que 'ao ler o documento, teve vontade de sentar e chorar junto com a nossa assistida'. O outro caso tratava-se de um homicídio com uma série de agravantes que tornavam bastante ruim o retrato do réu. O caso chegou para mim da seguinte forma: um cara asfixiou o chefe, cortou o corpo em pedaços, colocou dentro de uma mala e abandonou-a numa rodovia. No contato com o menino, vi que a história ia muito além do que aparecia no processo. Mais uma vez, pedi auxílio aos profissionais do CAM, e fizemos um atendimento conjunto. A história foi se revelando de outro modo. Tratava-se de um crime passional, envolvendo chefe e subordinado. Era uma relação amorosa muito complicada, o chefe era casado, a história acontecia às escondidas, tinha a questão da homossexualidade... Os profissionais do CAM fizeram todo um trabalho com a família do menino que resultou num relatório psicossocial fantástico, no qual essa história pôde aparecer. Este caso teve o júri adiado diversas vezes, sendo que no último que ocorreu, o promotor, diferente do primeiro caso, tentou desqualificar o trabalho do CAM dizendo que o menino precisava passar era por uma avaliação psiquiátrica. No final do júri, eu fui apresentar os profissionais do CAM ao promotor e disse a ele para ter mais cautela antes de insinuar a realização de um mau trabalho, pois ele nem conhecia os excelentes profissionais que haviam produzido aquele relatório. Para mim, o trabalho nesses dois casos só foi possivel porque contou com a atuação dos profissionais do CAM. Eu jamais conseguiria com o instrumental jurídico produzir um relatório daqueles (Defensor público, entrevista cedida para a pesquisadora em 30/10/2012).

Para Alexandre de Oliveira Henz, Maurício Lourenção Garcia, Samira Lima da Costa e Viviane Santalucia Maximino (2013), a produção de um trabalho (em)comum passa pela experiência de uma formação inventiva que opera o desafio de deformar. Os movimentos necessários para produzir esta (de)formação são: rompimento de fronteiras interespecíficas, exercício de experimentação frequente e investimento na constituição de equipes. $\mathrm{O}$ trabalho em equipe opera com multiplicidades, agenciamento de múltiplos encontros e, quando agenciado em ato, produz uma espécie de eixo transversal que problematiza as identidades profissionais e o paralelismo dos eixos comuns e específicos (HENZ et alii, 2013: 178).

De acordo com os autores (HENZ et alii, 2013), na construção de um plano comum não se trataria de uma metamorfose, no sentido do Serviço Social virar Psicologia, por exemplo. Neste processo, cria-se uma zona de perturbação entre as disciplinas, uma aproximação pela distância, que faz emergir "o comum”. Sua potência encontra-se justamente aí, em ser o lugar de qualquer um e, portanto, o virtual lugar de uma multidão em produção (MERHY, 2013: 31). No entanto, a produção de algo comum não constitui tarefa fácil. Os autores destacam que "o comum passou a ser visto como básico, mínimo, o inicial, um saber talvez menos importante (HENZ et alii, 2013: 181).

Michel Foucault, no curso Em Defesa da sociedade (2010), refere-se aos saberes sujeitados, desqualificados e, por isso, "menores". A emergência destes saberes se insere no processo que Foucault chamou de "disciplinamento dos saberes" (FOUCAULT, 2010: 146) 
que se dará a partir do século XVIII, junto ao desenvolvimento do regime disciplinar. Para ele, os saberes sujeitados são: "uma série de saberes que estavam desqualificados como saberes não conceituais, como saberes insuficientemente elaborados: saberes ingênuos, saberes hierarquicamente inferiores, saberes abaixo do nível do conhecimento ou da cientificidade requeridos" (FOUCAULT, 2010: 8).

Um olhar apressado sobre estas questões poderia levar a pensar que este processo de disciplinamento dos saberes impediria a emergência de arranjos que escapem à lógica disciplinar. Foucault destaca que o enfrentamento entre saberes não foi reduzido pelo disciplinamento. Para o autor, do ponto de vista da tecnologia, pode-se dizer que "o disciplinamento operado no decorrer do século XVIII foi eficaz e bem-sucedido; em compensação, no que se refere ao saber histórico, houve disciplinamento, mas esse processo não só não impediu, mas acabou fortalecendo, através de um jogo de confiscos e de contestações recíprocas, a história não estatal, a história descentralizada, a história dos sujeitos em luta" (FOUCAULT, 2010: 157).

Diante disso, indaga-se: a emergência do "plano comum" e dos "saberes menores" não possibilitaria certo desmanchamento/desestabilizações nos regimes disciplinares e nos modos de saber-fazer? As experiências de pôr-se ao lado, ao potencializarem certa abertura no coeficiente de transversalidade, não sinalizariam pistas para a construção de modos de saberfazer que tendam à "estética do caleidoscópio"?

Assim, aposta-se na abertura de brechas e furos nos muros dos territórios disciplinares, na produção de rachaduras no campo, tradicionalmente blindado dos encontros psi-jurídicos. Rachar não significa separar, dividir, esquadrinhar; pelo contrário, trata-se da operação de dar visibilidade "ao que se passa entre" (DELEUZE, 2010: 113), "às saliências e reentrâncias das práticas vizinhas" (RODRIGUES, 1998: 23).

\section{Pro-posições?}

- Uma das coisas que eu aprendi muito a gostar da Defensoria Pública é que a gente se aproxima muito mais de uma justiça real, concreta para as pessoas, assumindo mais explicitamente e comprometidamente essa parcialidade porque basicamente a gente erra muito em concepção. A gente pode estar pensando de uma determinada maneira e depois descobrir que tava errado. Assumir a parcialidade e lidar com erros parece garantir uma justiça melhor. A multiplicidade de posições. A Defensoria Pública pode atuar por duas partes que estão litigando. Assim, ela assume as duas posições e vê junto com as pessoas no que aquilo vai dar. O lugar de terceiro deixemos para o Judiciário" (Psicólogo) 
- "Inclusive a Defensoria vai defender o cara que entrou numa Defensoria esses dias armado, dizendo que a Defensoria o traiu. É uma discussão interessante" (Defensor público)

- Quem vai defender os defensores? (Pergunta - participante)

- "O CAM!" (Defensor público)

Risos!

(Roda de conversa PUC-SP, maio de 2012).

O jogo de deslocamentos enunciado pelos profissionais nesta roda de conversa nos convida a pensar numa lógica de desmanchamento de posições que abre a possibilidade para emergência de sentidos até antes não formulados: o gosto pela multiplicidade de posições, a possibilidade de brincar com ideia da "defesa" que se desloca do defensor para o CAM, ou ainda do conflito defensoria-usuário que ganha visibilidade, quando o "assistido" será ainda assim defendido. No percurso da pesquisa, a emergência destes deslocamentos e de outros mais sinalizou certas condições de possibilidade para produzir e legitimar outros modos de saberfazer nesse campo de batalha ainda e sempre em disputa, (re)conhecido como psi-jurídico.

Lourau (2001) nos lembra que a palavra campo (referindo-se à field theorie inglesa, mas o mesmo vale para o português) possui a polissemia de "terreno" e de "campo" teórico (p. 67). E nos coloca que a "chave dos campos"6 ou a "liberdade de movimentos" não é uma chave que habilita para a entrada num campo que se apresenta fechado.

Ao contrário, são as interferências que permitem sair do local onde se está para ir a um território livre. Assim, para Lourau, "nunca se pode falar de campo delimitado... o território devém rede. As marcas fogem como voo de pardal. Não há mais que interferências nos campos: campos de interferência" (LOURAU, 2001: 71, tradução da autora).

Critica-se, assim, a noção de campo como "substancialização metafísica das disciplinas científicas", cuja identidade estaria delimitada pelas fronteiras definidas pelo Estado. Ao contrário, Lourau sinaliza que "não há ruptura classificatória, mas ligação transdutiva ${ }^{7}$, encadeamento de enunciados entre diversos modos de discurso de registros, em geral, separados..." (LOURAU, 2001: 133, tradução da autora).

Assim, caminha-se menos para a ideia de um campo psi-jurídico como uma unidade finalmente integrada ou integral (como total) e mais para o campo implicacional, campo interferencial, que supõem o permanente exercício do entre posições e possibilitam o jogo da diferenciação, isto é, da variação permanente que impede tanto a homogeneização como o assujeitamento de um saber a outro. Recusa-se, desse modo, qualquer essência fixa - essa metafísica unitária das áreas profissionais -, rachando, assim, modos de saber-fazer que pretendem polir as formas e fôrmas das profissões. 
Neste entre posições, cabe lembrarmos de Foucault (2010: 151) e sua política da insurreição dos saberes menores como pistas para os processos de trabalho e de formação: insurreição não contra os saberes, mas “contra os efeitos do saber centralizador; fazer entrar no jogo os saberes locais “descontínuos, desclassificados, não legitimados”; produzir "análise das discursividades locais"; impugnar o despotismo que assujeita e submete em nome da ciência.

Por fim, retomando a enunciação de um defensor público, referindo-se aos encontros entre profissionais na Defensoria Pública - "para que aconteça, é necessário que os saberes se entreguem, opa, se integrem" -, pensamos que as condições de possibilidade para esta "entrega" estão postas. Resta saber se há dis-posição!

\section{Referências}

ALTOÉ, Sônia. Atualidade da psicologia jurídica. Psibrasil Revista de Pesquisadores da Psicologia no Brasil, 2001, http://biblioteca.cejamericas.org/bitstream/handle/2015/1400/psicologia_juridica.pdf?s equence=1\&isAllowed=y, acessado em 29 de agosto de 2019 .

ALVARENGA, Augusta Thereza. Histórico, fundamentos filosóficos e teórico-metodológicos da interdisciplinaridade. In: PHILIPPI JÚNIOR, Arlindo e SILVA NETO, Antônio. (orgs.) Interdisciplinaridade em ciência, tecnologia e inovação. Barueri: Manole, 2011.

ARAGON, Luís Eduardo. Percorrendo idiossincrasias do pensamento do luís no caminho de Simondon. Núcleo de Subjetividade PUC-SP, s/d, https://www.pucsp.br/nucleodesubjetividade/Textos/idiossincrasiasluis.pdf, acessado em 29 de agosto de 2019.

ARANTES, Esther Maria de Magalhães. Mediante quais práticas a Psicologia e o Direito pretendem discutir a relação? Anotações sobre o mal-estar. In: COIMBRA, Cecília Maria de Bouças, AYRES, Lygia Santa Maria e NASCIMENTO, Maria Lívia do (orgs.). PIVETES: encontros entre a psicologia e o judiciário. Curitiba: Juruá, 2008.

BAREMBLITT, Gregório. Compêndio de análise institucional e outras correntes: teoria e prática. $5^{\mathrm{a}}$ ed. Belo Horizonte: Instituto Felix Guattari, 2002.

BRITO, Leila Maria Torraca de. Anotações sobre a Psicologia Jurídica. Psicologia: Ciência e $\begin{array}{llllll}\text { Profissão, } 32 \quad \text { (num. } & \text { esp.), 2012, }\end{array}$ http://www.scielo.br/pdf/pcp/v32nspe/v32speca14.pdf, acessado em 29 de agosto de 2019.

CAVALCANTE, Paula Rosana. Contribuições da Psicologia no acesso à Justiça: reflexões sobre a atuação de psicólogas/os na Defensoria Pública do Estado de São Paulo. Dissertação de Mestrado. Programa de Pós-graduação do Instituto de Psicologia, Universidade de São Paulo, São Paulo, 2015.

CECCIM, Ricardo Burg. Equipe de saúde: a perspectiva entre-disciplinar na produção dos atos terapêuticos. Em: PINHEIRO, Roseni e MATTOS, Ruben Araújo de (orgs.) Cuidado: as fronteiras da integralidade. Rio de Janeiro: Hucitec, 2004. 
CECCIM, Ricardo Burg; FEUERWERKER, Laura. O quadrilátero da formação para área da saúde: ensino, gestão, atenção e controle social. Physis, Revista de Saúde Coletiva, Rio de Janeiro, 14(1): 41-65, 2004, http://www.scielo.br/pdf/physis/v14n1/v14n1a04.pdf, acessado em 29 de agosto de 2019.

DE SORDI, Mara Regina Lemes De; BAGNATO, Maria Helena Salgado. Subsídios para uma formação profissional crítico-reflexiva na área da saúde: o desafio da virada do século. Revista Latino-Americana de Enfermagem, Ribeirão Preto, vol. 6, $\mathrm{n}^{\circ}$ 2, abril de 1998, http://www.scielo.br/pdf/rlae/v6n2/13911.pdf, acessado em 29 de agosto de 2019.

DELEUZE, Gilles. Conversações (1972-1990). 2ªed. São Paulo: Ed. 34, 2010.

. Diferença e repetição. Tradução Luis Orlandi, Roberto Machado. $1^{\mathrm{a} e d . ~ S a ̃ o ~ P a u l o: ~}$ Paz e Terra, 2018.

FERNÁNDEZ, Ana María. Las lógicas colectivas: imaginarios, cuerpos y multiplicidades. $2^{\mathrm{a}}$ ed. Buenos Aires: Biblos, 2008.

FERREIRA NETO, João Leite. Psicologia, políticas públicas e o SUS. São Paulo: Escuta; Belo Horizonte: Fapemig, 2011.

FERRETTI, Celso João. Sociedade do conhecimento e educação profissional de nível técnico no Brasil. Cadernos de Pesquisa, São Paulo, vol. 38, no 135, dezembro de 2008, http://www.scielo.br/pdf/cp/v38n135/v38n135a05.pdf, acessado em 29 de agosto de 2019.

FOUCAULT, Michel. Em defesa da sociedade: curso no Collège de France (1975-1976). $2^{\mathrm{a}}$ ed. São Paulo: Editora WMF Martins Fontes, 2010.

. Vigiar e punir: nascimento da prisão. 31ª ed. Petrópolis: Vozes, 2006.

GUATTARI, Felix. Psicanálise e transversalidade: ensaios de Análise Institucional. São Paulo: Editora Ideias e Letras, 2004.

HECKERT, Ana Lúcia Coelho; PASSOS, Eduardo. Pesquisa-intervenção como método, a formação como intervenção. In: CARVALHO, Sérgio Resende; BARROS, Maria Elisabeth e FERIGATO, Sabrina (orgs.) Conexões: saúde coletiva e políticas de subjetividade. São Paulo: Hucitec, 2009.

HENZ, Alexandre de Oliveira. Formação como deformação: esgotamento entre Nietzsche e Deleuze. Revista Mal-estar e Subjetividade, Fortaleza, vol. 9(1), p. 135-159, março de 2009, http://pepsic.bvsalud.org/pdf/malestar/v9n1/06.pdf, acessado em 29 de agosto de 2019.

HENZ, Alexandre de Oliveira, GARCIA, Maurício Lourenção, DA COSTA Samira Lima e MAXIMINO, Viviane Santalucia. Trabalho entreprofissional: acerca do comum e a cerca do específico. In: CAPOZZOLO, Ângela Aparecida; CASETTO, Sidnei José e HENZ, Alexandre de Oliveira (orgs.) Clínica comum: itinerários de uma formação em saúde. São Paulo: Hucitec, 2013.

JAPIASSU, Hilton Ferreira. Interdisciplinaridade e patologia do saber. Rio de Janeiro: Imago, 1977.

KASTRUP, Virgínia. A invenção de si e do mundo: uma introdução do tempo e do coletivo no estudo da cognição. Belo Horizonte: Autêntica, 2007.

LAZZAROTTO, Gislei Domingas Romanzini. Pragmática de uma língua menor na formação 
em psicologia: um diário coletivo e políticas juvenis. Tese de doutorado. Universidade Federal do Rio Grande do Sul, Porto Alegre, 2009, https://lume.ufrgs.br/handle/10183/16912, acessado em 26 de agosto de 2019.

LOBO, Lilia Ferreira. Instituições e poder: racionalidade macropolítica e genealogia. Estudos de Psicologia, Natal, 2004, http://www.scielo.br/pdf/epsic/v9n2/a12v9n2.pdf, acessado em 29 de agosto de 2019.

LOURAU, René. Libertad de movimientos: una introducción al análisis institucional. Buenos Aires: Eudeba/ Universidad de Buenos Aires, 2001.

. René Lourau: analista institucional em tempo integral. São Paulo: Hucitec, 2004.

MERHY, Emerson Elias. Vivenciar um campo de formação de profissionais de saúde: dobrando em mim o fazer da Unifesp Baixada Santista. In: CAPOZZOLO, Ângela Aparecida; CASETTO, Sidnei José e HENZ, Alexandre de Oliveira (orgs.) Clínica comum: itinerários de uma formação em saúde. São Paulo: Hucitec, 2013.

OLIVEIRA, Renata Ghisleni de. Encontros psi-jurídicos na Defensoria Pública do Estado de São Paulo: entre saberes, transversalidades e itinerários de formação. Tese de Doutorado. Programa de Estudos Pós-graduados em Psicologia Social, Pontifícia Universidade Católica de São Paulo, São Paulo, 2015, https://tede2.pucsp.br/handle/handle/17108, acessado em 26 de agosto de 2019.

OURY, Jean. Itinerários de formação. (tradução: Jairo Goldberg). Revue Pratique $\mathrm{n}^{\circ} 1$, p. 42 50, 1991.

PASSOS, Eduardo. A construção da clínica comum e as áreas profissionais. In: CAPOZZOLO, Ângela Aparecida; CASETTO, Sidnei José e HENZ, Alexandre de Oliveira (orgs.) Clínica comum: itinerários de uma formação em saúde. São Paulo: Hucitec, 2013.

PASSOS, Eduardo; BARROS, Regina Benevides. A construção do plano da clínica e o conceito de transdisciplinaridade. Psicologia: Teoria e Pesquisa, Brasília, vol. 16, nº 1, p. 71-79, 2000, http://www.scielo.br/pdf/ptp/v16n1/4390.pdf, acessado em 29 de agosto de 2019.

RODRIGUES, Heliana de Barros Conde. A história oral como intercessor: em favor de uma dessujeição metodológica. Estudos e Pesquisas em Psicologia, Rio de Janeiro, vol. 10, $\mathrm{n}^{\mathrm{o}} 1$, abr. 2010, http://www.redalyc.org/articulo.oa?id=451844631013, acessado em 29 de agosto de 2019.

. Análise Institucional Francesa e Transformação Social: o tempo (e contratempo) das intervenções.In: RODRIGUES, Heliana de Barros Conde e ALTOÉ, Sônia (orgs.) SaúdeLoucura 8, Análise Institucional. São Paulo: Hucitec, 2004.

. Quando Clio encontra Psyche: pistas para um (des)caminho formativo. Cadernos Transdiciplinares, 1, p. 33-70, 1998.

Notas anti-panoptistas sobre o paradigma institucionalista. Preâmbulo políticoconceitual às aventuras históricas de "sócios" e "esquizos" no Rio de Janeiro. Revista Transversões, Rio de Janeiro, p. 169-199, 1999.

Renata Ghisleni de Oliveira Psicóloga e Mestra em Psicologia Social e Institucional pela UFRGS; Doutora em Psicologia Social pela PUC-SP; 
Pós-doutorado no Programa de Pós-graduação em Direito da UFMG. Integrante do Núcleo de Pesquisa em Psicologia Jurídica do Conselho Nacional de Desenvolvimento Científico e Tecnológico (NPPJ-CNPq). Email: reghisleni@yahoo.com.br

1 A expressão "menorizadas" é utilizada para dar visibilidade às desigualdades do sistema de justiça que,
historicamente, desqualificam e desvalorizam as solicitações da população pobre.
$2 \mathrm{Na}$ época da pesquisa, uma terceira frente de interdisciplinaridade se dava através da Assessoria Técnica
Psicossocial (ATP) - órgão que prestava assessoria à administração superior em questões referentes ao trabalho
dos psicólogos e assistentes sociais na Defensoria Pública. A ATP foi extinta no começo de 2017. Para mais
informações, sugere-se a leitura de Paula Rosana Cavalcante (2018), https://www.defensoria.sp.def.br/cadernos_defensoria/volume20.aspx, acessado em 26 de agosto de 2019.

${ }^{3} \mathrm{O}$ projeto de pesquisa foi aprovado pelo comitê de ética em pesquisa, de acordo com as normas estabelecidas para a realização de pesquisa com seres humanos pelo Conselho Nacional de Saúde (1996) - Resolução nº 196/96, através do registro $\mathrm{n}^{\circ}$ 11382312.5.0000.5482, na Plataforma Brasil.

${ }^{4}$ Projeto de formação com grupos de defensores públicos, desenvolvido em parceria com a Assessoria Técnica Psicossocial (ATP), Escola da Defensoria Pública (Edepe) e Núcleos de Pesquisa em Lógicas Institucionais e Coletivas e Psicanálise e Política do Programa de Estudos Pós-graduados da PUC-SP, compondo parte do processo formativo dos defensores aprovados no quinto concurso da carreira, no qual participou a autora do artigo e demais colegas de pesquisa nas funções de coordenação e de cronista (elaboração de narrativas a partir dos encontros).

${ }^{5}$ Projeto proposto por estagiário integrante do CAM, acompanhado na pesquisa, que contou com a participação de todos os atores da unidade de defensoria - estagiários de Psicologia, Serviço Social e Direito, psicólogos, assistentes sociais, defensores públicos e equipe administrativa -, promovendo debates sobre interdisciplinaridade e atuação interprofissional no âmbito do acesso à justiça.

${ }^{6}$ La clé des champs (1997) é o título do seu último trabalho e foi traduzido na edição espanhola por Libertad de movimentos (2001). "Liberdade de movimentos" é acepção que se utiliza mais comumente para esta expressão, conforme nota do tradutor.

${ }^{7}$ Lourau toma de empréstimo a noção de "transdução", definida por Gilbert Simondon. "Transdução é a operação física biológica, mental, social pela qual uma atividade se propaga gradativamente no interior de um domínio. Cada região que se forma serve de princípio de constituição à região seguinte. A modificação ocorre ao mesmo tempo em que se engendra a estrutura" (ARAGON, s/d: 8). Disponível em: http://www.pucsp.br/nucleodesubjetividade/Textos/idiossincrasiasluis.pdf, acessado em 10 de abril de 2020. 